\title{
ANÁLISE DA PERCEPÇÃO AMBIENTAL E DO POTENCIAL DO PAINEL FOTOVOLTAICO NA PERSPECTIVA DE AVICULTORES DE TOLEDO-PR
}

\author{
A.A.L.da Silva ${ }^{1}$; A.Stradiotto ${ }^{1 *}$; A.A.Saggin ${ }^{1}$ e L.T.Brandalise ${ }^{1}$ \\ 1 Universidade Estadual do Oeste do Paraná - UNIOESTE, 85809-110, Cascavel-PR, Brasil \\ *adriano.stradiotto@gmail.com
}

Artigo submetido em Fevereiro/2017 e aceito em xxxx/20xx

\section{RESUMO}

Este estudo buscou analisar a percepção ambiental dos avicultores do município de Toledo-PR e sua preocupação ecológica em relação às etapas da ACV - Análise do Ciclo de Vida do Painel Fotovoltaico. A pesquisa caracteriza-se como sendo descritiva e os dados são de fontes primárias. Foi aplicado um instrumento de pesquisa do tipo questionário, adaptado segundo o modelo VAPERCOM. Foi realizada a aplicação do questionário a 66 avicultores, sendo os dados apresentados através de gráficos, quadros e tabelas. Os resultados mostram que o produto, apesar de ser uma fonte de geração de energia limpa e renovável, apresenta gap's de percepção do consumidor quanto ao seu processo de produção e extração de matéria prima. Identificou-se, ainda, que os pesquisados apresentam pouco conhecimento sobre a ACV e sobre o produto, por não ser muito utilizado na região, influenciando diretamente no comportamento de compra do consumidor.

\section{ANALYSIS OF THE ENVIRONMENTAL PERCEPTION AND POTENTIAL OF THE PHOTOVOLTAIC PANEL IN THE PERSPECTIVE OF POULTRY FARMERS OF TOLEDO-PR}

\begin{abstract}
The present study aimed to analyse the environmental perception of poultry farmers of Toledo-PR city and their concern about the stages of (LCA) - Life-Cycle Analysis of the Photovoltaic Panel. The research is characterized as descriptive and the data is of primary sources. A research instrument type questionnaire, adapted according to the VAPERCOM model was, applied. The questionnaire was carried out at 66 poultry farmers, the data being presented through graphs, charts and tables.
\end{abstract}

The results show that the product, in spite of being a source of clean and renewable power generation, presents the consumer's perception gap as to their process of production and extraction of raw materials. It was found also that the respondents have little knowledge of the LCA and the product, that not widely used in the region, directly influencing the consumer buying behavior.

KEYWORDS: LCA, Environmental awareness, Sustainability in agribusiness, Photovoltaic panel. 


\section{INTRODUÇÃO}

O Brasil deverá ofertar internamente, em 2016, mais de 286 milhões de toneladas equivalente de petróleo (TEP) em energia para movimentar sua economia, e deste total 43,9\% são representados por fontes de energia renovável, o que coloca a matriz energética brasileira como sendo uma das mais limpas do mundo (MINISTÉRIO DE MINAS E ENERGIA - MME, 2016).

Em setembro de 2015 o Brasil formalizou à Organização das Nações Unidas - ONU seu compromisso em reduzir as suas emissões de carbono em 37\% em relação ao ano-base de 2005. Para esse desafio o país precisará percorrer um longo caminho, pois também não poderá abrir mão da melhoria nos seus indicadores socioeconômicos, elevando os padrões de vida para se equiparar aos países desenvolvidos e reduzindo o índice de pobreza. Para tal, fatalmente será necessário aumentar o consumo de energia para fazer frente ao seu crescimento econômico, o que pode dificultar ao país conseguir realizar esse compromisso até 2030, mantendo sua eficiência energética (EPE, 2016).

A energia solar aparece como uma forte tendência de alternativa energética, principalmente com o aumento do consumo de energia trazido pelo crescimento econômico dos países em desenvolvimento, como citam (CECONI, et al., 2010). Diante do crescimento econômico e populacional, percebe-se que o comportamento do consumidor e suas expectativas aumentam em relação à qualidade de vida; com isso, percebe-se também um crescimento na quantidade de energia necessária para manter esse padrão de vida, ao mesmo tempo em que aumenta a utilização ineficaz e o desperdício (RÜTHER, 2010).

Como forma de colaborar nesse ambiente de preocupações sócio-ambientais, a Análise do Ciclo de Vida do produto (ACV) é uma forma de avaliar os possíveis impactos ambientais quantitativos e qualitativos gerados por bens de consumo e serviços em todo o seu processo produtivo, distribuição, consumo e descarte ou reciclagem. Esse método permite que empresas e organizações possam realizar uma análise prática dos impactos ambientais causados por seus produtos ou serviços, e assim desenvolver um programa para contribuir com o meio ambiente, evitando ou até eliminando formas poluidoras, e promovendo uma condição de vida mais saudável (BLAICH; PINATTI, 2008).

Os produtos com tecnologia verde, ou seja, que têm seu processo de desenvolvimento e produção baseados no desenvolvimento sustentável, trazem inovação criativa e produtiva, gerando valor à empresa ou organização, e se expandindo para a sociedade na propagação de um meio ambiental mais saudável (SANTOS; OLIVEIRA, 2014). Neste sentido, os painéis fotovoltaicos são vistos como um produto verde, gerando energia limpa em um cenário de escassez de energia, o que viabiliza essa alternativa tecnológica com forte tendência de consumo e utilização devido à sua capacidade sustentável e renovável de gerar energia. Buscando contribuir com esse cenário de preocupações sustentáveis, a presente pesquisa visa responder a seguinte questão: qual a percepção dos avicultores na Análise do Ciclo de Vida dos painéis fotovoltaicos?

Neste sentido, este estudo tem como objetivo analisar o grau de percepção ambiental dos avicultores e sua preocupação ecológica em relação às etapas da ACV dos painéis fotovoltaicos. Esse produto é baseado em alta tecnologia e tem um grande potencial para geração de energia, podendo, assim, promover novos desafios sociais e rever posicionamentos nas questões climáticas diante do esgotamento dos recursos, além de contribuir significativamente para a segurança energética da população, de uma empresa, segmento e até mesmo de uma nação (HOPPMANN et al., 2014). A importância do estudo também se justifica pela responsabilidade crescente das empresas perante a sociedade, uma vez que a percepção dos consumidores torna-se a cada dia um fator crucial para formulação de suas estratégias e o planejamento de novas ações; busca-se, então, 
aumentar o nível de gestão empresarial assumindo que as expectativas e avaliações dos consumidores são muito relevantes para a sua competitividade e permanência no mercado (BRANDALISE, 2008, p. 135).

Assim, o presente estudo foi organizado da seguinte forma, após essa primeira parte introdutória: em sua segunda parte, apresenta-se a revisão de literatura abordando os temas pertinentes; na terceira, os procedimentos metodológicos utilizados para o desenvolvimento da pesquisa, abordados de forma qualitativa e quantitativa; na quarta seção, apresenta-se a análise dos resultados; e por fim, na quinta, as considerações finais, limitações do estudo e sugestões para pesquisas futuras.

\section{MATERIAIS E MÉTODOS}

Para atingir os objetivos propostos, o estudo apresenta uma pesquisa do tipo levantamento de dados; segundo Gil (2008), este método busca conhecer o comportamento de determinadas pessoas, solicitando informações acerca do problema estudado, para que posteriormente possam ser desenvolvidas as análises e conclusões dos dados coletados. O estudo também é caracterizado como pesquisa descritiva, onde segundo Vergara (1998) o foco é expor as características de uma determinada população ou fenômeno.

A pesquisa foi aplicada em julho de 2016, e a população estudada foi estimada através do levantamento de campo desenvolvido no município de Toledo, localizado na Região Oeste do Paraná, onde foram identificados 202 avicultores. Segundo Gil (2002), o levantamento necessita representar a população analisada, e somente poderia expressar 100\% da realidade caso fosse aplicado sobre a totalidade da população.

O critério para seleção das amostras foi definido de forma aleatória, sendo que o parâmetro estimado para o nível de confiança foi de $95 \%$, admitindo-se uma margem de erro máxima de $10 \%$ para mais ou para menos. O tamanho da amostra foi constituído de 66 avicultores, conforme a equação para estimativa da amostragem definida por Barbetta (2007):

$$
\mathrm{n}=\frac{\mathrm{N} *\left(1 /\left(E_{0}\right)^{2}\right)}{\mathrm{N}+\left(1 /\left(E_{0}\right)^{2}\right)}
$$

Onde:

$\begin{array}{lll}\mathrm{E}_{0} & = & \text { erro amostral tolerável; } \\ \mathrm{N} & = & \text { tamanho da população; } \\ \mathrm{n} & = & \text { tamanho da amostra. }\end{array}$

$\mathrm{O}$ instrumento para coleta de dados da pesquisa foi composto com base no modelo Brandalise (2008), denominado de VAPERCOM. Este modelo foi desenvolvido considerando: VA = variável ambiental; PER = percepção; e COM = comportamento de compra. O questionário foi adaptado para o alcance dos objetivos propostos, sem alterar a intenção proposta pelo modelo.

A partir disso, os dados primários foram obtidos pela aplicação do questionário composto por quatro conjuntos de questões fechadas e de múltipla escolha, no qual as alternativas seguem o modelo VAPERCOM. Para a análise dos dados, tabulação e qualificação utilizou-se o auxílio de 
softwares e planilhas eletrônicas, e através desse processo foram obtidos os resultados analisados. Quanto aos dados secundários, estes foram obtidos através de consultas a material bibliográfico e documental, sempre pertinentes ao estudo.

\subsection{Sobre o Modelo VAPERCOM}

O modelo VAPERCOM foi desenvolvido com o objetivo de buscar informações sobre a percepção do consumidor, sempre admitindo a questão ambiental nas etapas da ACV, e contemplando uma busca secundária para o quesito da competitividade organizacional (BRANDALISE et al., 2009).

Como essência do modelo VAPERCOM, consideram-se três variáveis que influenciam o consumidor e seu comportamento de compra, os quais sejam: a variável ambiental; os estímulos internos e externos, que impactam na percepção do consumidor e no processo de compra; e as influências sociais, mercadológicas e situacionais (BRANDALISE, 2006).

A aplicação dessa ferramenta passa por quatro etapas, que podem assim ser enumeradas: etapa 1 - caracterização do produto e do consumidor; etapa 2 - identificação dos indivíduos pesquisados, de sua percepção ambiental, do consumo ecológico e da visão quanto às etapas da ACV - Análise do Ciclo de Vida do Produto; etapa 3 - apontamento das discrepâncias entre as características do produto e as que o consumidor identifica; e etapa 4 - identificação de oportunidades de ações (BRANDALISE, 2006).

\section{REVISÃO DE LITERATURA}

Neste item são apresentados os conceitos relativos aos temas da Análise do Ciclo de Vida do produto (ACV), da percepção do consumidor, da sustentabilidade no agronegócio e dos painéis fotovoltaicos.

\subsection{Análise do Ciclo de Vida do produto (ACV)}

Adicionalmente aos fatores ambientais, a ACV estuda os impactos potenciais ao longo da vida de um produto, indo do seu berço ao seu túmulo, passando pela compra da matéria prima, processo produtivo, utilização e descarte. Essa técnica é muito valiosa por permitir avaliar os aspectos ambientais e impactos causados por um determinado produto (ABNT NBR ISO 14040, 2001).

Sendo uma técnica que avalia o desempenho ambiental de determinado produto ou serviço, a ACV também qualifica a energia e matéria prima utilizadas no ciclo produtivo ou do serviço prestado, identificando pontos de emissões de poluentes para a água, solo e ar que são oriundos do desenvolvimento dessa atividade (CLAUDINO e TALAMINI, 2012). Através dessa avaliação e identificação dos gargalos que causam danos ao meio ambiente e prejudicam a qualidade de vida, permite a identificação de oportunidades de melhoria e aperfeiçoamento do processo produtivo, implicando em práticas voltadas à preservação dos recursos naturais (QUEIROZ e GARCIA, 2010).

A consciência ambiental desponta como fator relevante na sociedade, tornando-se tema presente em muitos estudos acadêmicos que denotam forte preocupação com a sustentabilidade; isso vem influenciando muitas empresas em sua busca pela vantagem competitiva, fazendo com que busquem absorver o fato de que qualquer produto provoca impacto no meio ambiente 
(BRANDALISE, 2010, p.148). Considerando estes aspectos, aliados à crescente escassez dos recursos energéticos, a utilização de painéis fotovoltaicos surge como uma forte tendência, diante do seu potencial econômico e sócio-ambiental, principalmente quando utilizado em um setor onde a energia é essencial e impactante no custo do produto.

\subsection{Percepção do consumidor e percepção ambiental}

Sabe-se que uma das variáveis que mais afeta a decisão do consumidor no momento da uma compra é a relação com o preço e o desconto oferecido, percebendo-se que sua resposta pela aquisição do bem ou serviço sofre a influência direta desses fatores (ISABELLA et al., 2012).

Surgindo como um novo vetor a ser estudado, o comportamento de consumo ambiental aparece como preocupação crescente na área de marketing. Neste aspecto, pesquisas revelam que existe um distanciamento entre a consciência ambiental e o comportamento de consumo; os produtos ofertados, segundo essa hipótese, são apenas mecanismos de propaganda, não recebendo a preferência dos consumidores. Entretanto, cada vez mais esses indicadores estão sendo minimizados pela crescente preferência dos consumidores em relação aos produtos ecologicamente corretos (FREDERICO; QUEVEDO-SILVA; FREIRE, 2013).

A responsabilidade social das empresas e a percepção do consumidor devem estar baseadas em uma consciência clara dentro da esfera econômica, social e ambiental. É necessário que, ao serem protagonistas em seus atos de compra e produção, busquem informar, sensibilizar, mobilizar e motivar as mudanças de atitudes e comportamentos da sociedade consumista. Todas as ações individuais na esfera do consumo, independentemente de serem pessoas físicas ou jurídicas, são vistas como uma boa estratégia de mudanças rumo à sustentabilidade (BRANDALISE, 2010, p. 105).

Outro fator expressivo é o desenvolvimento sustentável, que aborda uma visão compartilhada de esforço mútuo das empresas em se manterem comprometidas na minimização dos impactos ambientais causados pela sua produção de bens ou serviços. Essa visão apresenta-se como oportunidade de vantagem competitiva, motivando a introdução de novos recursos tecnológicos, inclusive através de parcerias com outros países que já estejam em grau mais avançado de vivência sócio-ambiental (CHENG, FET e HOLMEN (2010).

\subsection{Sustentabilidade no agronegócio}

O agronegócio é atividade âncora da economia brasileira, gerando empregos, equilibrando a balança comercial, evitando a importação e garantindo alimentos a custos acessíveis e com alta qualidade, promovendo a economia e gerando riquezas ao país. Porém, agregados a esses benefícios vêm sempre a preocupação e os desafios para o setor; um desses grandes desafios é o constante crescimento da percepção da população com relação à sustentabilidade ambiental, trazendo ao debate uma produção cada vez mais sustentável e com menor impacto ao meio ambiente (CLAUDINO; TALAMINI, 2013).

O desenvolvimento sustentável abrange três pontos fundamentais, os quais promovem os ambientes ecologicamente correto, socialmente justo e economicamente viável. Uma visão geral sobre o agronegócio, considerando as oportunidades e desafios desse setor, considera todo o processo de produção, financiamentos, políticas, tecnologias, uso racional dos recursos e, finalmente, a sustentabilidade do negócio (FERNANDES 2010). 
Diante desse ambiente produtivo, todas as variáveis produtivas impactam diretamente no ambiente ao seu redor. E o equilíbrio entre essas variáveis e o meio-ambiente permite que as organizações produtivas alcancem uma atuação sustentável, que será fator-chave para o seu sucesso junto ao mercado onde atuam, e à sociedade onde estão inseridas. Cada vez mais os consumidores adquirem consciência crítica com relação aos cuidados para com o meio-ambiente, e esse aspecto passa a influenciar diretamente no seu comportamento de compra.

\subsection{Painéis Fotovoltaicos}

Os painéis solares fotovoltaicos não geram emissões de poluentes, apresentando-se como fonte de energia limpa, se comparados ao uso de fontes de carvão ou gás; entretanto, seu uso associado a bancos de baterias podem significar certo impacto ambiental e preocupação quanto à poluição residual. A fabricação dessas baterias e seus componentes, incluindo aí o seu descarte, podem trazer danos ambientais; entretanto, alternativas encontradas como na Alemanha permitem a reciclagem de quase $100 \%$ desses componentes, podendo servir de modelo para os demais países (HOPPMANN et al., 2014).

No Brasil, a Resolução Normativa 482/2012 da Agência Nacional de Energia Elétrica ANEEL determina que os sistemas fotovoltaicos integrados à rede das operadoras não utilizem banco de baterias, armazenando "créditos" da energia gerada na própria rede da concessionária de energia. Para tal, utilizam-se medidores especiais de energia elétrica (bidirecionais), os quais medem tanto a energia consumida da rede da concessionária quanto a energia que foi fornecida pelo sistema fotovoltaico para essa mesma rede. Assim, dispensa-se o uso de bancos de baterias, tornando a solução adotada no Brasil ainda mais sustentável (ANEEL, 2012).

No ano de 2013 eram encontrados pequenos projetos de produção baseados nesta fonte de energia renovável; já em 2015 o cenário torna-se mais otimista, diante da escassez de fontes geradoras na matriz energética convencional brasileira e do crescimento dos preços praticados pelas concessionárias de energia elétrica. Esses fatos viabilizaram ainda mais os projetos de construção de parques solares. Outro fato importante foi a aprovação da lei que isenta de cobrança de impostos a importação de componentes para a fabricação dos painéis fotovoltaicos, além do projeto em andamento que solicita a isenção de tributos federais sobre os equipamentos (ORGIS, 2015). A verdade é que a energia fotovoltaica está crescendo no Brasil, e esse fato acompanha a queda do custo de geração de energia, conforme apresentado na Figura 1.

Figura 1: Custo de geração de energia fotovoltaica (em US\$/KWh)

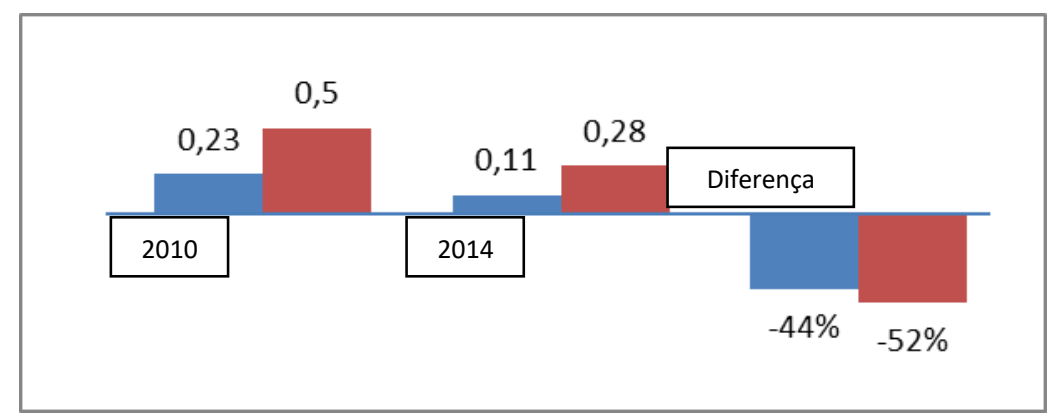

Fonte: Adaptado de ORGIS, 2015.

Como fica claro na figura acima, verifica-se uma queda acentuada no custo de geração de energia fotovoltaica nos últimos anos, principalmente diante do emprego de novas tecnologias de produção e dos crescentes (ainda que tímidos) incentivos governamentais. Assim, tem-se um 
cenário cada vez mais favorável ao emprego dessa alternativa de geração renovável de energia elétrica.

\section{RESULTADOS E DISCUSSÃO}

Nesta seção são apresentados os resultados da pesquisa, seguindo as etapas do modelo VAPERCOM, bem como discussões teóricas acerca dos resultados obtidos. Como ponto de partida, é apresentada na primeira etapa a caracterização do produto objeto do estudo.

\subsection{Caracterização do produto}

Os painéis fotovoltaicos são formados pela associação de dois ou mais módulos fotovoltaicos, sendo esses formados basicamente por uma associação de células fotovoltaicas, e tendo por função converter a energia do sol em energia elétrica. Quando esses sistemas são conectados à rede pública de distribuição de eletricidade, passa a ter a função de operar como um gerador de energia elétrica, que acumula créditos em energia na rede elétrica da concessionária.

Os sistemas fotovoltaicos podem ser baseados em diversas tecnologias, porém sua matéria prima bruta principal é o silício, o qual deve possuir um grau de pureza extremamente elevado. Esse silício é encapsulado com vidro fotovoltaico, que necessita ser ultra-puro e com baixo teor de ferro, desenvolvido para refletir menos a luz e absorver o máximo de energia solar que passar por ele. Toda essa estrutura de módulos solares é fixada através de estruturas metálicas, normalmente manufaturada com alumínio, de forma a aumentar sua durabilidade e diminuir o peso total da estrutura nos locais de instalação. Esse arranjo de painéis solares é conectado a um dispositivo denominado inversor, o qual transforma a energia gerada em corrente contínua para corrente alternada, de forma a adequar essa energia para conexão à rede da concessionária. Além desses equipamentos, o sistema conta com dispositivos de proteção contra surtos, choques, curto circuitos e descargas atmosféricas, além de um completo sistema de aterramento.

O quadro 1 apresenta a caracterização do produto objeto do estudo, e os aspectos relacionados nas etapas da $\mathrm{ACV}$.

Quadro 1: Etapas da ACV e Aspectos Relacionados

\begin{tabular}{|c|c|c|c|}
\hline ETAPAS DA ACV & \multicolumn{2}{|c|}{$\begin{array}{l}\text { Aspectos ambientais relacionados à fabricação do } \\
\text { painel fotovoltaico }\end{array}$} & $\begin{array}{c}\text { Característica } \\
\text { ecológica }\end{array}$ \\
\hline \multirow[b]{2}{*}{ Matéria prima } & Origem dos recursos & $\begin{array}{l}\text { Médio, alguns são } \\
\text { renováveis. }\end{array}$ & Mediana \\
\hline & $\begin{array}{l}\text { Impacto ambiental na } \\
\text { extração }\end{array}$ & 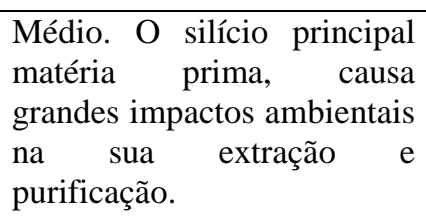 & Mediana \\
\hline \multirow[b]{2}{*}{ Processo de produção } & Consumo de energia & Alto. & Fraca \\
\hline & $\begin{array}{l}\text { Geração de resíduos } \\
\text { sólidos, efluentes líquidos }\end{array}$ & $\begin{array}{l}\text { Médio. O impacto sobre o } \\
\text { meio físico está ligado a } \\
\text { emissão de Hexafluoreto de } \\
\text { Enxofre, usado para limpar }\end{array}$ & Fraca \\
\hline
\end{tabular}




\begin{tabular}{|c|c|c|c|}
\hline & e emissões atmosféricas & $\begin{array}{l}\text { reatores, que é um potente } \\
\text { gás de efeito estufa, além de } \\
\text { chuva ácida; e está ligado ao } \\
\text { tetracloreto de silício, uma } \\
\text { substância tóxica, que reage } \\
\text { violentamente com a água. }\end{array}$ & \\
\hline & $\begin{array}{c}\text { Consumo de } \\
\text { combustível } \\
\text { no transporte e } \\
\text { distribuição }\end{array}$ & $\begin{array}{l}\text { Produto é geralmente } \\
\text { importado. }\end{array}$ & Fraca \\
\hline \multirow{3}{*}{ Utilização } & Vida útil do produto & $\begin{array}{l}\text { Longa. } \quad 40 \\
\text { aproximadamente. }\end{array}$ & Forte \\
\hline & $\begin{array}{c}\text { Potencial de } \\
\text { contaminação } \\
\text { ao meio ambiente }\end{array}$ & Baixo. & Forte \\
\hline & Embalagem & Baixa. Embalagem Plástica & Forte \\
\hline \multirow{3}{*}{ Pós-utilização } & $\begin{array}{l}\text { Possibilidade de } \\
\text { reutilização }\end{array}$ & $\begin{array}{l}\text { Alguns componentes podem } \\
\text { ser reaproveitados ou } \\
\text { reciclados. Mas a vida útil } \\
\text { do conjunto é longa. }\end{array}$ & Forte \\
\hline & $\begin{array}{l}\text { Potencialidade de } \\
\text { reaproveitamento de } \\
\text { componentes }\end{array}$ & $\begin{array}{l}\text { Média. Alguns componentes } \\
\text { podem ser reaproveitados. }\end{array}$ & Forte \\
\hline & $\begin{array}{l}\text { Possibilidade de } \\
\text { reciclagem }\end{array}$ & $\begin{array}{l}\text { Alta. A maior parte da } \\
\text { composição é formada por } \\
\text { plástico e vidro. }\end{array}$ & Forte \\
\hline \multirow{3}{*}{ Descarte } & $\begin{array}{l}\text { Periculosidade ou } \\
\text { toxidade }\end{array}$ & $\begin{array}{l}\text { Médio. Alguns componentes } \\
\text { são tóxicos. }\end{array}$ & Mediana \\
\hline & Volume do material & Médio. & Mediana \\
\hline & Biodegrabilidade & Não é biodegradável. & Mediana \\
\hline
\end{tabular}

Fonte: Adaptado de Brandalise (2008, p.150).

Nas etapas de matéria-prima e processo de produção, o painel fotovoltaico apresenta um desempenho mediano, uma vez que seus insumos originam-se do extrativismo mineral e apresentam certo grau de degradação ambiental.

Quanto ao seu processo produtivo, demanda um volume considerável de energia e gera resíduos sólidos e emissões de poluentes, o que acarreta uma característica ambiental fraca. Por outro lado, as etapas de utilização, pós-utilização e descarte apresentam em grande parte características fortes, devido à durabilidade e longevidade do produto. Ao mesmo tempo, por seus componentes serem em grande parte de plástico e vidro, apresentam grande potencial de reutilização e reciclagem.

$\mathrm{Na}$ fase seguinte deste modelo, identifica-se o perfil do público alvo, sua percepção ambiental e do consumo ecológico, bem como sua preocupação nas etapas da ACV. 


\subsection{Conjunto 01 - Caracterização do pesquisado}

Conforme os dados coletados, a questão gênero mostra que $94 \%$ dos pesquisados são do gênero masculino, e $6 \%$ apenas representam o gênero feminino, conforme apresentado no Gráfico 02. Quanto à faixa etária dos pesquisados, podemos verificar que $47,69 \%$ estão entre 41 e 55 anos de idade, conforme mostra o Gráfico 03.

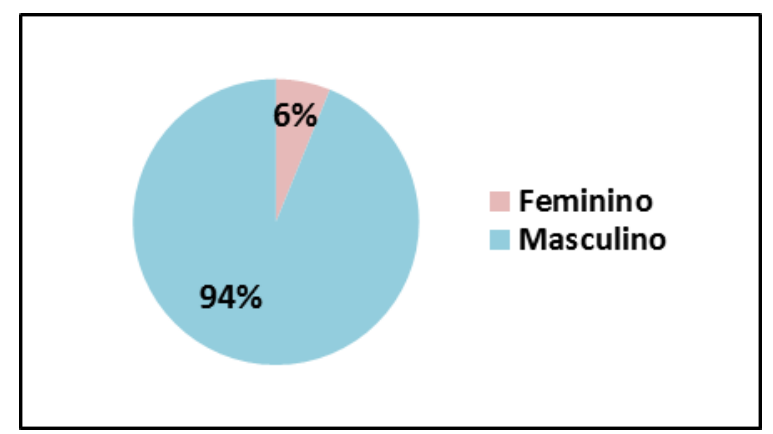

Gráfico 02: Sexo dos pesquisados

Fonte: Questionário aplicado (2016)

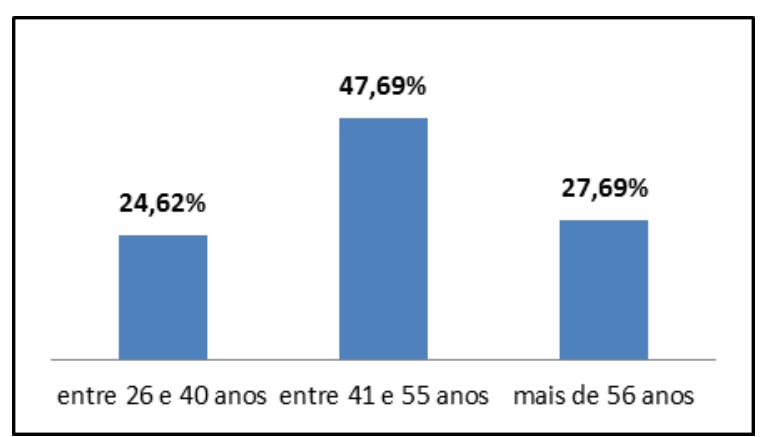

Gráfico 03: Faixa etária dos pesquisados

Fonte: Questionário aplicado (2016)

Na continuidade das análises, as questões estão voltadas ao perfil dos pesquisados, conforme apresentado na Tabela 01. Nessa fase investiga-se sobre os custos com energia elétrica em cada propriedade, devido ao objeto do estudo ser uma fonte de energia renovável. Quanto a essa questão, observa-se que 43,08\% tem custo entre $\mathrm{R} \$ 1.501,00$ a $\mathrm{R} \$ 3.500,00$. Quanto à questão da principal fonte para obtenção de informações sobre o meio ambiente, constata-se que 84,62\% das fontes são através da mídia (televisão, internet, rádio, etc.). Sobre o conhecimento sobre ACV, 70,77\% dos pesquisados não conhece sobre o assunto. Para concluir a análise do perfil do pesquisado, questionou-se sobre o conhecimento a respeito do impacto causado pelo painel fotovoltaico, mesmo sendo um produto gerador de energia limpa, onde $60 \%$ dos pesquisados respondeu que não tinha conhecimento sobre esse fato.

Tabela 01: Perfil dos pesquisados

\begin{tabular}{|c|c|c|c|c|c|}
\hline \multirow{2}{*}{$\begin{array}{l}\text { Custo médio } \\
\text { Mensal com } \\
\text { energia } \\
\text { elétrica }\end{array}$} & Até ${ }_{1.500}^{\mathrm{R} \$}$ & $\begin{array}{c}\mathrm{R} \$ 1.501 \mathrm{a} \\
\mathrm{R} \$ 3.500\end{array}$ & $\begin{array}{c}\mathrm{R} \$ 3.501 \mathrm{a} \\
\mathrm{R} \$ 5.000\end{array}$ & $\begin{array}{rr}\mathrm{R} \$ 5.001 \mathrm{a} & \mathrm{R} \$ \\
8.000 & \end{array}$ & $\begin{array}{c}\text { Acima de R\$ } \\
8.000\end{array}$ \\
\hline & $29,23 \%$ & $43,08 \%$ & $26,15 \%$ & $0 \%$ & $1,54 \%$ \\
\hline \multirow{2}{*}{$\begin{array}{l}\text { Principal fonte } \\
\text { de } \\
\text { informações } \\
\text { ambientais }\end{array}$} & Escola & Mídia & Família & Rótulos/embalagens & Amigos \\
\hline & $0 \%$ & $84,62 \%$ & $6,15 \%$ & $7,69 \%$ & $1,54 \%$ \\
\hline \multirow{2}{*}{\multicolumn{3}{|c|}{ Conhecimento sobre ACV }} & Sim & Tenho dúvidas & Não \\
\hline & & & $0,77 \%$ & $18,46 \%$ & $70,77 \%$ \\
\hline \multicolumn{3}{|c|}{ Impacto ambiental do painel } & Sim & Tenho dúvidas & Não \\
\hline
\end{tabular}




\begin{tabular}{|l|c|c|c|}
\hline fotovoltaico & $13,85 \%$ & $26,15 \%$ & $60 \%$ \\
\hline
\end{tabular}

Fonte: Questionário aplicado (2016)

$\mathrm{Na}$ sequência, são apresentados os dados referentes ao conjunto de questões voltadas à percepção ambiental dos pesquisados, considerando os elementos redução, reutilização e reciclabilidade dos recursos.

\subsection{Conjunto 02 - Percepção ambiental}

A Tabela 02 mostra a frequência das respostas em relação às questões 07 a 11 do instrumento de coleta de dados. Os totais apurados em cada questão foram: $A=101, B=82, C=95$, $\mathrm{D}=33$ e $\mathrm{E}=19$. Observa-se que a alternativa $\mathrm{A}$ (Sempre) é a que mais se destaca, seguida por $\mathrm{C}$ (Algumas vezes), aparecendo nas questões 10 e 11.

Tabela 02: Frequência de respostas do conjunto percepção ambiental

\begin{tabular}{|c|c|c|c|c|c|c|}
\hline \multicolumn{2}{|r|}{ PERCEPÇÃO AMBIENTAL } & \multirow{2}{*}{$\begin{array}{c}\stackrel{0}{\mathscr{Z}} \\
\stackrel{\Xi}{\mathscr{D}} \\
8\end{array}$} & \multirow{2}{*}{ 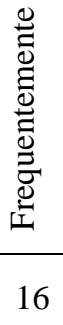 } & \multirow{2}{*}{ 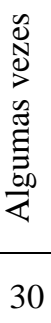 } & \multirow{2}{*}{ 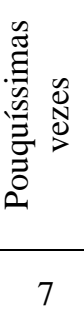 } & \multirow{2}{*}{$\begin{array}{l}\underset{\mathscr{Z}}{\Xi} \\
5\end{array}$} \\
\hline 07 & Antes de jogar algo no lixo, você pensa em como poderia reutilizá-lo? & & & & & \\
\hline 08 & Você é adepto da reciclagem? & 15 & 16 & 20 & 10 & 5 \\
\hline 09 & $\begin{array}{l}\text { Você separa o lixo que pode ser reciclado (papel, plástico, alumínio, } \\
\text { vidro, metais) e os dispõe para coleta? }\end{array}$ & 17 & 12 & 19 & 11 & 7 \\
\hline 10 & $\begin{array}{l}\text { Apaga as luzes, desliga TV, aparelho de som, ventilador / aquecedor } \\
\text { quando sai do ambiente? }\end{array}$ & 30 & 17 & 13 & 4 & 2 \\
\hline 11 & $\begin{array}{l}\text { Procura não deixar a torneira aberta ao escovar os dentes ou ao fazer a } \\
\text { barba? }\end{array}$ & 31 & 21 & 13 & 1 & 0 \\
\hline & TOTAL & 101 & 82 & 95 & 33 & 19 \\
\hline
\end{tabular}

Fonte: Questionário aplicado (2016)

Neste conjunto apresentam-se as médias e o tratamento estatístico de pontuação, de acordo com os pesos e elaboração do grau de percepção ambiental. Conforme apresentado na Tabela 03, foram as seguintes frequências de respostas obtidas: $\mathrm{A}($ sempre $)=4$ pontos; $\mathrm{B}$ (frequentemente) $=3$ pontos; $\mathrm{C}($ algumas vezes $)=2$ pontos $; \mathrm{D}$ (pouquíssimas vezes $)=1$ ponto e $\mathrm{E}($ nunca $)=0$. 
Tabela 03: Alocação dos pesos e mensuração de grau de percepção ambiental

\begin{tabular}{|c|c|c|}
\hline (a) $\mathrm{N}^{\circ}$ RESPOSTAS & (b) VALORES & (a X b) RESULTADO \\
\hline$A=101$ & 4 & 404 \\
\hline $\mathrm{B}=82$ & 3 & 246 \\
\hline $\mathrm{C}=95$ & 2 & 190 \\
\hline $\mathrm{D}=33$ & 1 & 33 \\
\hline $\mathrm{E}=19$ & 0 & 0 \\
\hline \multicolumn{2}{|c|}{ (c) SOMA DOS RESULTADOS } & 873 \\
\hline (d) $\mathrm{N}^{\circ}$ DE QUESTÕES & & 330 \\
\hline$(\mathbf{e}=\mathbf{c} / \mathbf{d})$ RESULTADO & & 2,6 \\
\hline
\end{tabular}

Fonte: Questionário aplicado (2016)

A Tabela 04 classifica o grau de percepção ambiental dos pesquisados. O valor alcançado de 2,6 foi obtido de acordo com os pesos alocados a cada alternativa, e o resultado mostra que os pesquisados possuem percepção ecológica.

Tabela 04: Classificação do grau de percepção ambiental da amostra

\begin{tabular}{|l|c|}
\hline \multicolumn{1}{|c|}{ Grau de percepção em relação às questões ambientais } & Valores \\
\hline A) Possui alta percepção ecológica & Entre 3,3 e 4,0 \\
\hline B) Possui percepção ecológica & Entre 2,5 e 3,2 \\
\hline C) Possui potenciais traços de percepção ambiental & Entre 1,7 e 2,4 \\
\hline D) Possui poucos traços de percepção ambiental & Entre 0,9 e 1,6 \\
\hline E) Não possui percepção ecológica & Até 0,8 \\
\hline
\end{tabular}

Fonte: Questionário aplicado (2016)

$\mathrm{Na}$ sequência do levantamento, apresentam-se os dados referentes ao conjunto de questões voltadas ao consumo ecológico, ou seja, como é o comportamento de compra e consumo dos pesquisados, considerando os elementos materiais renováveis, consumo de energia na utilização do produto, a vida útil do produto, reutilização e reciclabilidade. As questões de 12 a 21 são apresentadas na Tabela 05.

\subsection{Conjunto 03 - Conjunto ecológico}

A frequência de respostas foi: $A=121, B=106, C=236, D=124$ e $E=73$. Observa-se que a alternativa $C$ é a que mais se destaca, não sendo a mais apontada apenas nas questões 15 e 18 . Conclui-se, então, que os pesquisados algumas vezes buscam melhorar continuamente seu modo de consumo. Destacam-se as respostas das questões 15, onde a alternativa $\mathrm{A}$ foi destaque quanto à valorização do fabricante ecologicamente correto, e destaque para a alternativa A na questão 18, mostrando consciência perante o consumo de energia na compra de produtos. 
Tabela 05: Frequência de respostas do conjunto consumo ecológico

\begin{tabular}{|c|c|c|c|c|c|c|}
\hline & CONJUNTO ECOLÓGICO & 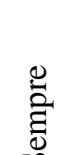 & 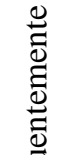 & 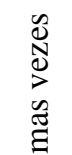 & 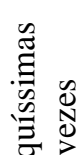 & $\stackrel{\Xi}{\Xi}$ \\
\hline 12 & Você considera a variável ambiental quando da compra de um produto? & 12 & 11 & 25 & 12 & 6 \\
\hline 13 & $\begin{array}{l}\text { Ao comprar você se deixar influenciar pela propaganda, pelos amigos ou pela } \\
\text { família em relação às questões ambientais? }\end{array}$ & 11 & 8 & 29 & 13 & 5 \\
\hline 14 & Ao comprar, você procura saber se o fabricante pratica ações ambientais? & 6 & 9 & 21 & 18 & 12 \\
\hline 15 & $\begin{array}{l}\text { Ao comprar, você valoriza o fabricante que tem 'postura' ecologicamente } \\
\text { correta? }\end{array}$ & 21 & 10 & 17 & 12 & 6 \\
\hline 16 & $\begin{array}{l}\text { Antes da compra você verifica rótulos e embalagens, para identificar um } \\
\text { 'produto' ecologicamente correto? }\end{array}$ & 9 & 9 & 23 & 15 & 10 \\
\hline 17 & $\begin{array}{l}\text { Procura comprar produtos e/ou embalagens fabricados com material reciclado } \\
\text { ou que tem potencial para serem reciclados? }\end{array}$ & 6 & 10 & 21 & 16 & 13 \\
\hline 18 & Você verifica o consumo de energia quando da compra de um produto? & 29 & 13 & 17 & 4 & 3 \\
\hline 19 & $\begin{array}{l}\text { Você compra produtos biodegradáveis? - destruição do produto por } \\
\text { microrganismos }\end{array}$ & 0 & 11 & 30 & 18 & 7 \\
\hline 20 & Você se dispõe a pagar mais por um produto ecologicamente correto? & 11 & 14 & 29 & 7 & 5 \\
\hline 21 & $\begin{array}{l}\text { Você se dispõe a mudar de marca de produto para auxiliar na conservação do } \\
\text { meio ambiente? }\end{array}$ & 16 & 11 & 24 & 9 & 6 \\
\hline & TOTAL & 121 & 106 & 236 & 124 & 73 \\
\hline
\end{tabular}

Fonte: Questionário aplicado (2016)

Para a análise deste conjunto é apresentada a Tabela 06, a qual apresenta os valores às respostas: $\mathrm{A}($ sempre $)=4$ pontos; $\mathrm{B}($ frequentemente $)=3$ pontos; $\mathrm{C}($ algumas vezes $)=2$ pontos; $\mathrm{D}$ $($ pouquíssimas vezes $)=1$ ponto e $\mathrm{E}($ nunca $)=0$.

Tabela 06: Alocação dos pesos e mensuração de grau de consumo ecológico

\begin{tabular}{|c|c|c|}
\hline (a) $\mathrm{N}^{\circ}$ RESPOSTAS & (b) VALORES & (a X b) RESULTADO \\
\hline$A=121$ & 4 & 484 \\
\hline $\mathrm{B}=106$ & 3 & 318 \\
\hline $\mathrm{C}=236$ & 2 & 472 \\
\hline $\mathrm{D}=124$ & 1 & 124 \\
\hline $\mathrm{E}=73$ & 0 & 0 \\
\hline \multicolumn{2}{|c|}{ (c) SOMA DOS RESULTADOS } & 1398 \\
\hline (d) $\mathrm{N}^{\circ}$ DE QUESTÕ̃ES & & 660 \\
\hline$(\mathbf{e}=\mathbf{c} / \mathbf{d})$ RESULTADO & & 2,1 \\
\hline
\end{tabular}

Fonte: Questionário aplicado (2016) 
O resultado obtido foi um Grau de Consumo Ecológico de 2,1. Conclui-se, conforme mostra a Tabela 07 abaixo, que os pesquisados possuem potenciais possibilidades de tornarem-se consumidores ecológicos.

Tabela 07: Classificação do grau de consumo ecológico da amostra

\begin{tabular}{|l|c|}
\hline \multicolumn{1}{|c|}{ Grau de percepção em relação às questões ambientais } & Valores \\
\hline A) Consumo ecológico & Entre 3,3 e 4,0 \\
\hline B) Grande possibilidade de tornar-se um consumidor ecológico 2,5 e 3,2 \\
\hline C) Potencial possibilidade de tornar-se um consumidor ecológico & Entre 1,7 e 2,4 \\
\hline D) Fraca possibilidade de tornar-se um consumidor ecológico & Entre 0,9 e 1,6 \\
\hline E) Não é um consumidor ecológico & Até 0,8 \\
\hline
\end{tabular}

Fonte: Questionário aplicado (2016)

A questão número 22 do instrumento de coleta de dados é referente especificamente ao produto objeto do estudo, onde se questiona quanto ao pesquisado já utilizar painéis fotovoltaicos. Neste quesito, constatou-se que $100 \%$ dos pesquisados não utiliza o produto. O principal motivo identificado é em relação ao preço, onde $62,12 \%$ dos pesquisados assinala ser esse o maior motivo de não consumo desse produto.

O alto valor do investimento para a instalação de painéis fotovoltaicos é discutido em estudos nacionais e internacionais sobre o tema e é destacado como um dos principais motivos da baixa utilização dos sistemas fotovoltaicos em áreas rurais. Byrne et al. (2005) em seu estudo ainda concluem uma inviabilidade na utilização de energia fotovoltaica em aviários, devido ao subsídio fornecido pelo governo norte americano aos produtores rurais sobre o valor da energia elétrica das redes públicas. Nascimento (2011), em sua análise de viabilidade, corrobora com tais constatações.

Outra parte dos pesquisados $(37,88 \%)$ ainda não conhecem o produto painel fotovoltaico. Esse resultado indica para uma oportunidade de divulgação e utilização dos painéis fotovoltaicos no meio rural, pois como indicado nos estudos de Van Campen, Guidi e Best (2000) e Byrne et al. (2005) os sistemas fotovoltaicos são utizados internacionalmente na produção avícola tanto de frangos de corte quanto em granjas de produção de ovos.

O conjunto 04, que comporta as questões 23 a 37, representa o último conjunto do instrumento de coleta de dados, e investiga sobre as etapas da ACV, tais como a preocupação quanto às características ambientais nessa etapa, estágios do ciclo de vida do produto, desde a matéria prima ao descarte.

\subsection{Conjunto 04 - Etapas da ACV}

As frequências observadas nesse conjunto são: $A=210, B=242, C=344, D=189$ e $E=5$. O destaque foi a "Média preocupação", que teve a maioria em todos os totais parciais, conforme mostra a Tabela 08. Em outras palavras, não há uma efetiva preocupação em relação ao ciclo de vida do produto, o que pode justificar o não conhecimento das etapas da ACV. Podemos destacar que os produtores em sua maioria têm uma certa preocupação com o meio ambiente, o quesito "nenhuma preocupação" foi pouco utilizado nas escolhas.

Quanto a cada etapa da ACV, podemos dar ênfase ao segundo quesito mais escolhido pelos agricultores que foi, "Frequentemente me preocupo" em relação à matéria prima, processos de produção, utilização do produto e pós-utilização do produto. Apesar do pouco ou nenhum 
conhecimento sobre ACV e os processos de produção, os produtores apresentam uma certa preocupação com os impactos ambientais e suas consequências no meio ambiente. Quanto ao descarte do produto, o segundo quesito mais escolhido entre os agricultores foi "Forte preocupação", a analogia para essa escolha é a presença de muitas palestras e acesso a informações a respeito do correto descarte de produtos agrotóxicos no meio rural, sua correta utilização e descarte desses produtos pode ter sido a motivação dessa escolha.

Tabela 08: Classificação do grau de consumo ecológico da amostra

\begin{tabular}{|c|c|c|c|c|c|c|}
\hline \multicolumn{2}{|c|}{ CONJUNTO 04 - ETAPAS ACV } & 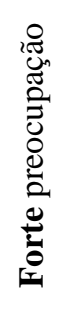 & 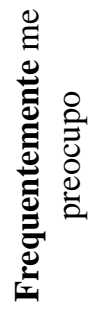 & 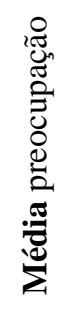 & 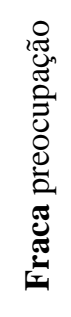 & 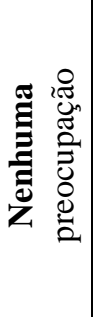 \\
\hline \multicolumn{7}{|c|}{ Em relação à matéria prima indique o grau de preocupação com: } \\
\hline 23 & Origem dos recursos (se são renováveis) & 9 & 17 & 28 & 12 & 0 \\
\hline 24 & Impacto ambiental na extração (e no transporte) & 12 & 17 & 26 & 11 & 0 \\
\hline & Total Parcial & 21 & 34 & 54 & 23 & $\mathbf{0}$ \\
\hline \multicolumn{7}{|c|}{ Em relação ao processo de produção indique o grau de preocupação com: } \\
\hline 25 & Consumo de energia (na produção) & 21 & 16 & 21 & 8 & 0 \\
\hline 26 & Geração de resíduos sólidos, efluentes líquidos e emissões atmosféricas & 10 & 17 & 24 & 15 & 0 \\
\hline 27 & Consumo de combustível na armazenagem e/ou transporte e distribuição & 14 & 15 & 22 & 15 & 0 \\
\hline & Total Parcial & 45 & 48 & 67 & 38 & $\mathbf{0}$ \\
\hline \multicolumn{7}{|c|}{ Em relação à utilização do produto indique o grau de preocupação com: } \\
\hline 28 & Vida útil do produto & 15 & 19 & 21 & 11 & 0 \\
\hline 29 & Necessidade de energia & 17 & 15 & 20 & 13 & 1 \\
\hline 30 & Potencial contaminação ao meio ambiente & 16 & 18 & 18 & 13 & 1 \\
\hline 31 & Embalagem (tipo e/ou volume) & 5 & 16 & 30 & 13 & 2 \\
\hline & Total Parcial & 53 & 68 & 89 & 50 & 4 \\
\hline \multicolumn{7}{|c|}{ Em relação à pós-utilização do produto indique o grau de preocupação com: } \\
\hline 32 & Possibilidade de reutilização & 13 & 17 & 23 & 12 & 1 \\
\hline 33 & Potencialidade de reaproveitamento de componentes & 11 & 14 & 27 & 14 & 0 \\
\hline 34 & Possibilidade de reciclagem & 16 & 13 & 22 & 15 & 0 \\
\hline & Total Parcial & 40 & 44 & 72 & 41 & 1 \\
\hline \multicolumn{7}{|c|}{ Em relação ao descarte do produto indique o grau de preocupação com: } \\
\hline 35 & Periculosidade ou toxidade & 29 & 17 & 10 & 10 & 0 \\
\hline 36 & Volume de material (incluindo embalagem) & 9 & 20 & 26 & 11 & 0 \\
\hline 37 & Biodegradabilidade - destruição do produto por microrganismos & 13 & 11 & 26 & 16 & 0 \\
\hline \multicolumn{2}{|r|}{ Total Parcial } & 51 & 48 & 62 & 37 & $\mathbf{0}$ \\
\hline \multicolumn{2}{|r|}{ TOTAL GERAL } & 210 & 242 & 344 & 189 & 5 \\
\hline
\end{tabular}

Fonte: Questionário aplicado (2016) 
Conforme a Tabela 09 que se refere à alocação dos pesos e mensuração do grau de preocupação com a $\mathrm{ACV}$, o valor obtido foi de 2,4.

Tabela 09: Alocação dos pesos e mensuração do grau de preocupação com a ACV

\begin{tabular}{|c|c|c|}
\hline (a) $\mathrm{N}^{\circ}$ RESPOSTAS & (b) VALORES & (a X b) RESULTADO \\
\hline$A=210$ & 4 & 840 \\
\hline $\mathrm{B}=242$ & 3 & 726 \\
\hline $\mathrm{C}=344$ & 2 & 688 \\
\hline $\mathrm{D}=189$ & 1 & 189 \\
\hline$E=5$ & 0 & 0 \\
\hline \multicolumn{2}{|c|}{ (c) SOMA DOS RESULTADOS } & 2443 \\
\hline (d) $\mathrm{N}^{\circ}$ DE QUESTÕES & & 990 \\
\hline$(\mathbf{e}=\mathbf{c} / \mathbf{d})$ RESULTADO & & 2,4 \\
\hline
\end{tabular}

Fonte: Questionário aplicado (2016)

O resultado mostra uma mediana preocupação com o ciclo de vida do produto, conforme apresentado na Tabela 10. Essa mensuração pode ser justificada devido ao fato de que poucos produtores conhecem ou ouviram falar sobre ACV, sabendo a importância em relação aos cuidados com o meio ambiente e a correta utilização dos recursos naturais, as respostas em torno da "mediana preocupação" foi considerada uma opção razoável e expressa essa dúvida entre eles.

O baixo conhecimento sobre ACV no meio rural é explicado por Claudino e Talamini (2013) como decorrência da baixa quantidade de pesquisas com essa abordagem no Brasil, apesar de ser um tema que vem ganhando espaço pela conscientização e preocupação da população com processos de produção mais limpos.

Tabela 10: Classificação do grau de preocupação do consumidor quanto à ACV

\begin{tabular}{|l|c|}
\hline \multicolumn{1}{|c|}{ Grau de percepção em relação às questões ambientais } & Valores \\
\hline A) Forte preocupação & Entre 3,3 e 4,0 \\
\hline B) Frequente preocupação & Entre 2,5 e 3,2 \\
\hline C) Mediana preocupação & Entre 1,7 e 2,4 \\
\hline D) Fraca Preocupação & Entre 0,9 e 1,6 \\
\hline E) Nenhuma preocupação & Até 0,8 \\
\hline
\end{tabular}

Fonte: Questionário aplicado (2016)

\subsection{Comparação entre as características do produto e as que o consumidor percebe}

Nesta etapa, apresenta-se o mapeamento do produto e a percepção ecológica do consumidor em relação às etapas da ACV, com base no Quadro 01. Para evidenciar a discrepância entre as características do produto nas etapas da ACV, e as características que o consumidor pesquisado observa nestas mesmas etapas, foi desenvolvida a Tabela 11 como instrumento auxiliar a este mapeamento. 
Tabela 11: Mapa do produto e da preocupação do consumidor amostrado

\begin{tabular}{|c|c|c|}
\hline \multirow{2}{*}{ Ciclo de Vida do Produto - ACV } & \multicolumn{2}{|c|}{ Características do produto X Preocupação do consumidor } \\
\cline { 2 - 3 } & $\begin{array}{c}\text { Características do Painel } \\
\text { Fotovoltaico }\end{array}$ & Preocupação do consumidor \\
\hline Matéria Prima & Mediana & Mediana \\
\hline Processo de produção & Fraca & Mediana \\
\hline Utilização do produto & Forte & Mediana \\
\hline Pós-utilização & Forte & Mediana \\
\hline Descarte & Mediana & Mediana \\
\hline
\end{tabular}

Fonte: Questionário aplicado (2016)

Conforme apresentado na Tabela 11, o consumidor tem uma mediana preocupação com as características do produto nas etapas da ACV, conforme demonstrado na Tabela 10. O produto, por sua vez, apresenta algumas características distintas em relação à percepção dos consumidores.

O Gráfico 05 ilustra os Gap's existentes entre as características do produto, destacados pela linha azul (contínua), e a preocupação do consumidor em relação às etapas da ACV, destacados pela linha vermelha (tracejada).

Gráfico 05: Representação polar da caracterização do produto e da preocupação do consumidor nas etapas da ACV

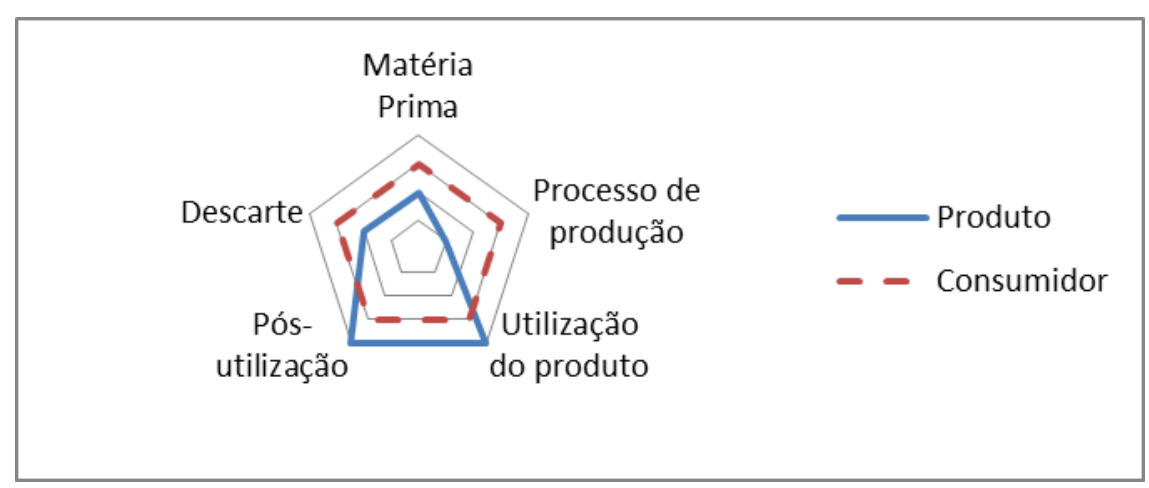

Fonte: Questionário aplicado (2016)

A quarta etapa apresenta a definição de oportunidades de ações e melhorias, passíveis de implantação nas etapas da ACV.

\subsection{Identificação de oportunidades de ações}

Conforme o mapa do produto demonstrado na Tabela 11, o mais relevante gap do painel fotovoltaico é identificado em seu processo de produção. Mesmo se tratando de um produto geralmente importado, sua produção gera alguns impactos ambientais e emissão de poluentes, além de utilizar considerável quantidade de energia em sua produção, opondo-se ao seu propósito próprio de gerador de energia limpa e renovável. 
Em relação ao gap identificado no mapa perante a preocupação do consumidor, a qual apresenta mediana preocupação nas etapas da ACV, este pode ser justificado pela falta de conhecimento a respeito dos painéis fotovoltaicos e seu processo de produção. Ao mesmo tempo, essa percepção também pode estar ligada à questão da baixa utilização desse produto na região, que distancia ainda mais o consumidor em relação às características do produto.

\section{CONCLUSÃO}

O presente estudo contribui para o entendimento da percepção ambiental dos avicultores e sua preocupação ecológica em relação às características sócio-ambientais do painel fotovoltaico, desde a aquisição da matéria-prima até seu descarte.

Os avicultores pesquisados buscam melhorar continuamente seu modo de consumo indicando a existência de potenciais possibilidades de tornarem-se consumidores ecológicos. Além disso, destaca-se que os avicultores em sua maioria têm relativa preocupação com o meio ambiente, evidenciando-se, assim, a existência de percepção ecológica no público analisado.

Uma das grandes contribuições trazidas por esta pesquisa é a identificação da importância em se conhecer as etapas da ACV de um produto. No caso específico do painel fotovoltaico, identificou-se que apesar de ser um gerador de energia limpa e renovável, apresenta um significativo impacto negativo ao meio ambiente com relação à extração de sua matéria prima e ao consumo de energia em sua produção.

Em relação à percepção dos avicultores sobre as etapas da ACV do painel fotovoltaico, constatou-se mediana preocupação, evidenciando a inexistência de uma preocupação efetiva acerca da análise do ciclo de vida dos painéis fotovoltaicos, que pode ser justificada pelo baixo conhecimento do produto e também das etapas de seu ciclo de vida.

Com relação à utilização dos painéis fotovoltaicos nas propriedades avícolas, contatou-se que dentre os pesquisados não há utilização dessa fonte de energia renovável. Os motivos identificados nessa pesquisa que levam à não utilização da energia fotovoltaica é o valor do investimento necessário e em grande parte dos casos a falta de conhecimento sobre esse sistema de geração de energia.

Com o desenvolvimento desta pesquisa foi possível identificar a forte preocupação dos avicultores com o consumo de energia em sua propriedade, permitindo inferir que políticas de divulgação ao uso de painéis fotovoltaicos poderiam estimular a utilização desse tipo de energia nas propriedades avícolas.

Para o meio empresarial, a ACV é uma importante ferramenta e que possibilita uma melhor gestão através do conhecimento do produto e do seu público alvo. Essa tomada de consciência empresarial pode ser muito impactante no processo de tomada de decisão, tanto quanto a mudanças nos níveis estratégico, tático ou operacional da organização, sempre buscando a perfeita harmonia entre esferas econômica, social e ambiental.

\section{AGRADECIMENTOS}

Os autores agradecem aos revisores da Revista Produção e Desenvolvimento pelas sugestões e recomendações para aprimoramento do artigo. 


\section{REFERÊNCIAS}

ABNT - ASSOCIAÇÃO BRASILEIRA DE NORMAS TÉCNICAS. NBR ISO 14040: Gestão ambiental - Avaliação do ciclo de vida - Princípios e estrutura. Rio de Janeiro, p.1-10, 2001

ANEEL - ASSOCIAÇÃO NACIONAL DE ENERGIA ELÉTRICA. Resolução Normativa no 482 , de 17 de Abril de 2012. Disponível em: <http:// www2.aneel.gov.br/cedoc/bren2012482.pdf. Acesso em: 31 de jul. 2016

BARBETTA, P. A. Estatística aplicada às ciências sociais. Florianópolis. UFSC, 2007. 316 p.

BLAICH, Leonardo Michel. PINATTI, Antonio Eduardo. Análise do Ciclo de Vida do produto e o Ecodesing. Revista de Estudos Universitários, v.34, [S.1.], p.55-64, set. 2008

BRANDALISE, Loreni T. Modelo de suporte à gestão organizacional com base no comportamento do consumidor considerando sua percepção da variável ambiental nas etapas da análise do ciclo de vida do produto. $2006.195 \mathrm{f}$. Tese (Doutorado em Engenharia de Produção) - Programa de Pós-Graduação em Engenharia de Produção Universidade Federal de Santa Catarina, Florianópolis, 2006

BRANDALISE, Loreni Teresinha. A Percepção do consumidor na análise do ciclo de vida do produto: um modelo de apoio à gestão empresarial. Cascavel: EDUNIOESTE, 2008. 200 p.

BRANDALISE, L. T. BERTOLINI, Geysler R. F. ROJO, Cláudio A. LEZANA, Álvaro G. R. POSSAMAI, Osmar. A percepção e o comportamento ambiental dos universitários em relação ao grau de educação ambiental. Gestão \& Produção, v. 16, n. 2, p. 273-285, 2009

BYRNE, J.; GLOVER, L.; HEGEDUS, S.; VANWICKLEN, G. The potential for solar electric applications for delaware's poultry farms. Disponível em: <http://www.seu-de.org/docs/PV_Poultry_Report_2005.pdf> Acesso em: 18 de dez. 2016

CECONI, M. et al. Solar irradiation numerical modeling as alternative method in evaluating of available energy potential. Rev. Geogr. Acadêmica, v.4, n.2, p.41-52, 2010

CHENG, Y. FET, Annik M. HOLMEN, Elsebeth. Using a Hexagonal Balanced Scorecard approach to integrate Corporate Sustainability into Strategy. Department of Industrial Economics and Technology Management Norwegian University of Science and Technology Trondheim, NO 7491, NORWAY, 2010

CLAUDINO, Edison S. TALAMINI, Edson. Análise do Ciclo de Vida (ACV) aplicada ao agronegócio: uma revisão de literatura. Revista Brasileira de Engenharia Agrícola e Ambiental, v.17, n.1, p.77-85, 2013

EPE - EMPRESA DE PESQUISA ENERGÉTICA. O Compromisso do Brasil no Combate às Mudanças Climáticas: Produção e Uso de Energia. Rio de Janeiro. Ministério de Minas e Energia. Jun., 2016

FERNANDES, Elizabeth Nogueira. Inovação tecnológica sustentável no agronegócio do leite. Disponível em: <http://pt.slideshare.net/Inovatecjf/inovao-tecnolgica-sustentvel-no-agronegcio-do-leite>. Acesso em: 18 de jul. 2016

FREDERICO, E.; QUEVEDO-SILVA, F.; FREIRE, O. B. D. L. Acquiring Consumer Trust: Minimizing the Gap Between Environmental Concern and Environmental Consumption. Revista de Gestão Ambiental e Sustentabilidade, v. 2, n. 2, p. 50-70, 2013

GIL, Antonio Carlos. Como elaborar projetos de pesquisa. 4. ed. São paulo: Atlas, 2002. 175 p.

GIL, Antonio Carlos. Métodos e técnicas de pesquisa social. 6. ed. São Paulo: Atlas, 2008. 200 p.

HOPPMANN, J., PETERS M., SCHNEIDER M., HOFFMANN, V.H. The economic viability of battery storage for residential solar photovoltaic systems - A review and a simulation model. Renewable and Sustainable Energy Reviews, v. 39, n. July, p. 1101-1118, 2014

ISABELLA, G. et al. Influence of Discount Price Announcements on Consumer'S Behavior. Influencia De Los Avisos De Descuento Sobre El Comportamiento De Los Consumidores., v. 52, n. 6, p. 657-671, 2012

MINISTÉRIO DE MINAS E ENERGIA - MME. Matriz energética de 2016 terá maior participação das energias renováveis. Disponível em: <http://www.brasil.gov.br/infraestrutura/2016/matriz-energetica-de-2016-tera-maiorparticipacao-das-energias-renovaveis> Acesso em: 17 de jul. 2016

NASCIMENTO, L. A. B. Análise Energética Na Avicultura De Corte: Estudo De Viabilidade Econômica para um Sistema de Geração de Energia Elétrica Eólico-Fotovoltaico Conectado à Rede. 2011. 131 f. Dissertação - Programa de Pós-Graduação em Engenharia Elétrica, UTFPR - Área de Concentração: Sistemas e Processamento de Energia. (2011) 
ORGIS, Guido. Leilões colocam a luz do sol na matriz energética brasileira. 2015. Disponível em: <http://www.gazetadopovo.com.br/economia/leiloes-colocam-a-luz-do-sol-na-matriz-energetica-brasileira5mqilb6ywpw45obrcfe61jk7x>. Acesso em: 18 de jul., 2016

QUEIROZ, G. C.; GARCIA, E. E. C. Reciclagem de sacolas plásticas de polietileno em termos de inventário de ciclo de vida. Revista Polimeros, v.20, p.401-406, 2010

RÜTHER, Ricardo. Relatório da sessão "Energias alternativas e potencial da energia solar fotovoltaica no Brasil." Parc. Estrat. Ed. Esp. Brasília-DF, v.15, n.31, p.273-286, Jul-Dez. 2010

VAN CAMPEN, B., GUIDI, D., \& BEST, G. Energia solar fotovoltaica para la agricultura y desarrollo rural sostenibles - Documento de Trabajo sobre Medio Ambiente y Recursos Naturales. FAO: Roma. (2000). VERGARA, Sylvia C. Projeto e relatórios de pesquisa em administração. 2.ed. São Paulo: Editora Atlas S.A., 1998. 